\title{
Assessment of outcomes of heart diseases in pregnancy: A cross sectional study in tertiary healthcare teaching institute in metropolitan city
}

\author{
Shaifali Patil ${ }^{1}$, Shivali Tripathi ${ }^{2, *}$, Utkarsha Patil $^{3}$ \\ ${ }^{\mathbf{1}}$ Associate Professor, ${ }^{\mathbf{J} J u n i o r ~ R e s i d e n t ~ I I I, ~}{ }^{\mathbf{P}}$ Assistant Professor, Dept. of Obstetrics and Gynecology, MGM Medical College \\ Hospital, Kalamboli, Maharashtra, India \\ *Corresponding Author: \\ Email: researchexpert3@gmail.com
}

\begin{abstract}
Introduction: World is still facing heart diseases in pregnancy as a major problem, particularly in poor countries. Although the reported incidence varies between 0.1 and 4\%, 1-3 cardiac disease remains a significant cause of maternal death worldwide. Cardiac disease in the pregnant patient can present challenges in cardiovascular and maternal-fetal management.in normal patients, pregnancy imposes some dramatic physiologic changes.

Materials and Methods: This observational study was conducted in the department of obstetrics and gynecology of M.G.M healthcare institute, Kalamboli, Maharashtra, India. This study includes total of 8 pregnant women, both referred and registered cases with history of cardiac disease were admitted in obstetric ward from January 2016 to September 2016.

Results: $75 \%$ of our study cases were between the age group of 20 years to 25 years, whereas $25 \%$ cases presented between the age group of 26 years to 30 years. This study reports the most common lesion as RHD with mitral stenosis. $38 \%$ of the patients from our study had Rheumatic heart disease and most of the patients had more than one lesion.

Discussion: According to present study, the cardiac disease appears to be a risk factor for maternal and neonatal morbidity and mortality. Rheumatic heart disease was observed to be the predominant lesion in our case series.
\end{abstract}

Conclusion: Heart disease in pregnancy is a high risk condition. It is a major determinant of pregnancy and its outcome.

Keywords: Heart diseases in pregnancy, Pre-Eclampsia, Pregnancy induced hypertension, RHD in pregnancy.

\section{Introduction}

It is well known that pregnancy has a major effect on the cardiovascular system, and it is an important determinant of many conditions, those are associated with a significant risk of maternal and foetal morbidity and mortality. It has been reported that $0.2-0.4 \%$ of all pregnancies are complicated by cardiovascular disease. Though mortality rates are lower, heart diseases in pregnancy are the important indirect cause of maternal mortality globally. ${ }^{1}$ Many poor countries are facing heart diseases in pregnancy as a public health concern. Although the reported incidence varies between 0.1 and $4 \%, 1-3$ cardiac disease remains a significant cause of maternal death worldwide. ${ }^{2}$ However in India, the prevalence of cardiovascular diseases in pregnancy lied between $0.3-3.5 \%$. In the presence of maternal heart disease, the circulatory changes of pregnancy may result in decompensation or death of mother or fetus. ${ }^{3}$ Though the major cause of cardiac disease in poor countries is Rheumatic heart disease (RHD), but it is uncommon in developed countries. ${ }^{2}$ Based on the location of the mother, variation in disease rates and epidemiology were observed. ${ }^{1}$ Worldwide, hypertensive disease in pregnancy is by far the most prevalent cardiovascular disorder, complicating $2-8 \%$ of all pregnancies in the Western world. Rheumatic heart disease is common in developing countries but are now rare in the Western world. ${ }^{1}$ Heart diseases in the pregnancy may present challenges in management of pregnancy, since pregnancy is associated with various physiologic changes on cardiovascular systems i.e. an increase in plasma volume and cardiac output by almost half times, $17 \%$ increase in resting pulse. The heart rate comes to normal physiologic state within 10 days after the delivery; and stroke volume, cardiac output, and systemic vascular resistance return to the pre-pregnancy state by 3 months after the delivery. ${ }^{4}$ We carried out this present study to assess various factors associated with heart diseases in pregnancy, and hence to evaluate its maternal and foetal outcomes.

\section{Materials and Methods}

The present retrospective observational study was conducted among total of 8 pregnant women, both referred and registered cases with history of cardiac disease were admitted in obstetric ward from January 2016 to September 2016, in the department of obstetrics and gynecology of MGM hospital, Kalamboli, Maharashtra, India. Baseline data recorded included including age, parity, gestational age, type of lesion, duration of disease, time of diagnosis, treatment history, and mode of delivery, indications of caesarean section, admissions of ICU, neonatal outcome and admission to NICU were noted. Grading of heart diseases was done using NYHA classification of cardiac diseases.

Grade I: patients with cardiac disease have no limitations of physical activity. Ordinary activity does not cause undue fatigue, palpitations, dyspnoea or angina

Grade II: patients with cardiac disease have slight limitations of physical activity. Ordinary activity causes undue fatigue, palpitations, dyspnoea or angina. 
Grade III: patients with cardiac disease have marked limitations of physical activity, less than ordinary activity causes undue symptoms.

Grade IV: patients with cardiac disease have an inability to carry out physical activities. Symptoms present even at rest.

\section{Results}

The present study was conducted among 8 ANC cases with heart diseases admitted under department of obstetrics and gynecology of Mahatma Gandhi Medical College Kalamboli. Out of 8 patients admitted, 6 cases were observed between the age group of 20 years to 25 years, whereas 2 cases presented between the age group of 26 years to 30 years (Table 1). 4 (50\%) cases were primigravida whereas $50 \%$ cases were multipara (Fig. 1). Similarly, 4 cases $(50 \%)$ delivered at term, while 4 $(50 \%)$ had a preterm delivery (Table 2 ). We assessed their ANC registration history, it was observed that three cases were booked and five were unbooked cases. 3 cases had Rheumatic heart disease and most of the patients had more than one lesion. RHD with mitral stenosis was reported to be the most common lesion. Surgical correction was done prior to pregnancy in 2 patients. Out of these one was primigravida, which was a previously diagnosed at the age of 5 years as a case of aortic stenosis, managed with ballon aortic valvoplasty at the age of 21 years (Table 3). Another case was G3P2L1D1 with 36 weeks of gestation with known case of Rheumatic heart disease with percutaneous ballon mitral valvotomy done during her previous pregnancy. Most of the patients (63\%) were delivered through Caesarean sections, done for obstetric indications. $75 \%$ of post-delivery cases required ICU admissions, those were predominantly unregistered ANC cases (Fig. 1) (Table 4). 38\% of babies delivered to these study subjects required NICU admissions after delivery (Table 5).

Table 1: Distribution of cases according to their age

\begin{tabular}{|l|c|c|}
\hline $\begin{array}{c}\text { Age group of } \\
\text { cases }\end{array}$ & $\begin{array}{c}\text { No of } \\
\text { patients }\end{array}$ & Percentage \\
\hline Less than 20 & 0 & 0 \\
\hline 21 to 25 YRS & 6 & 75 \\
\hline 26 to 30 YRS & 2 & 25 \\
\hline Total & 8 & $100 \%$ \\
\hline
\end{tabular}

Table 2: Distribution of cases according to their time of delivery

\begin{tabular}{|l|c|c|}
\hline Time of delivery & $\begin{array}{c}\text { No of } \\
\text { patients }\end{array}$ & Percentage \\
\hline Term & 4 & 50 \\
\hline Preterm & 4 & 50 \\
\hline Total & 8 & $100 \%$ \\
\hline
\end{tabular}

Table 3: Distribution of cases according to their type of cardiac lesion

\begin{tabular}{|l|c|c|}
\hline \multicolumn{1}{|c|}{ Type of cardiac lesion } & $\begin{array}{c}\text { No of } \\
\text { patients }\end{array}$ & \% \\
\hline *RHD with MS & 3 & 38 \\
\hline $\begin{array}{l}\text { Severe *MS with } \\
\text { *MR/PAH }\end{array}$ & 2 & 25 \\
\hline $\begin{array}{l}\text { As with bicuspid aortic } \\
\text { valve }\end{array}$ & 1 & 13 \\
\hline $\begin{array}{l}\text { Complete AV-canal } \\
\text { defect }\end{array}$ & 1 & 13 \\
\hline $\begin{array}{l}\text { *HOCM with diastolic } \\
\text { dysfunction }\end{array}$ & 1 & 13 \\
\hline Total & 8 & $100 \%$ \\
\hline
\end{tabular}

*RHD: Rheumatic heart disease, MS: Mitral Stenosis, MR: Mitral regurgitation, PAH: Pulmonary artery hypertension, HOCM: Hypertrophic obstructive cardiomyopathy

Table 4: Distribution of cases according to their post-delivery status

\begin{tabular}{|l|c|c|}
\hline \multicolumn{1}{|c|}{ Post-delivery status } & $\begin{array}{c}\text { No of } \\
\text { cases }\end{array}$ & $\boldsymbol{\%}$ \\
\hline ICU admission & 6 & 75 \\
\hline Ward admission & 2 & 25 \\
\hline No of deaths & 1 & 13 \\
\hline
\end{tabular}

Table 5: Distribution of cases according to neonatal status of heart disease cases

\begin{tabular}{|l|c|c|}
\hline Neonatal status & $\begin{array}{c}\text { Number } \\
\text { of cases }\end{array}$ & $\boldsymbol{\%}$ \\
\hline Shifted for NICU care & 3 & 38 \\
\hline Shifted to mother-side & 5 & 62 \\
\hline Total & 8 & $100 \%$ \\
\hline
\end{tabular}

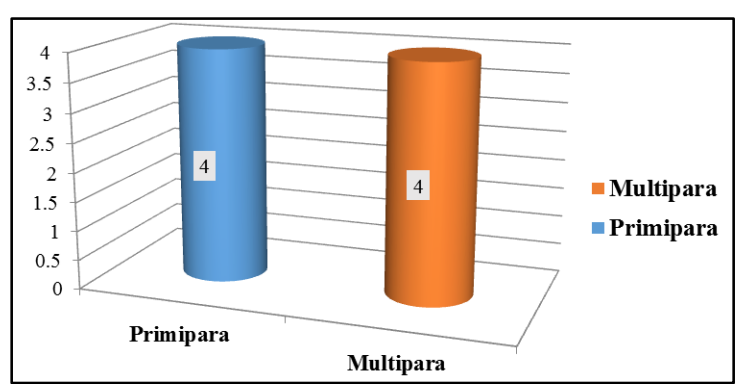

Fig. 1: Distribution of cases according to their order of parity 


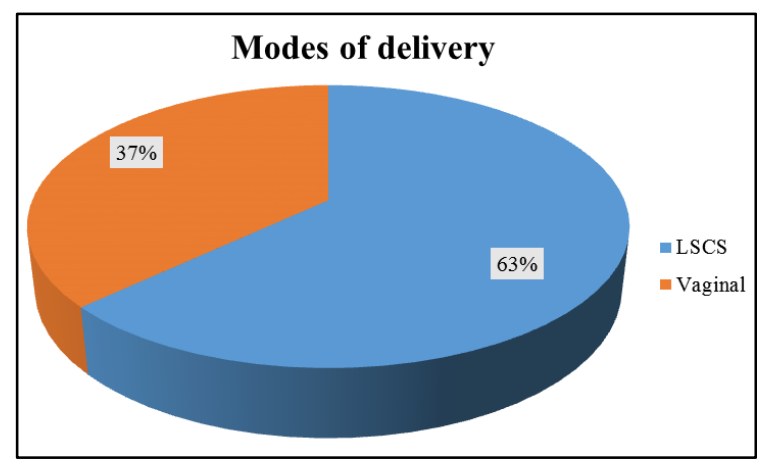

Fig. 2: Distribution of cases according to their modes of delivery

\section{Discussion}

In the current study we determined the type of cardiac lesion and assessed foeto-maternal outcome in patients with cardiac disease. It appears that the heart diseases play as an important risk factor and contributes for significant maternal and neonatal morbidity. In our study the predominant lesion was Rheumatic heart disease. Similar results were found by Subbaiah M et al, they found that majority of their study subjects with cardiac diseases in pregnancy were having rheumatic heart diseases $(64 \%)^{5}$ and Hiralal $\mathrm{M}$ et al also found that RHD was the principal cause of cardiac lesion was rheumatic heart disease among $69 \%$ cases followed by congenital heart disease among $21 \%$ of their study cases. $^{3}$ Mitral stenosis was found to be the most common lesion, with two cases underwent surgical correction before pregnancy. $63 \%$ patients underwent caesarean delivery. However Liu $\mathrm{H}$ et al in their study found that main heart diseases in pregnancy were arrhythmia $(\mathrm{n}=359,31.4 \%)$, congenital heart disease (CHD; $\mathrm{n}=291,25.5 \%)$, and myocarditis and its sequelae $(n=284,24.9 \%) .{ }^{6}$ Complications were found more among un-registered cases. Thus the key to safe pregnancy care in the context of cardiac disease is prenatal assessment. One patient with preterm delivery delivered outside, was admitted in ICU, died subsequently. In the prediction of adverse maternal and foetal outcome, it is helpful to focus on maternal functional status in addition to the type of cardiac abnormality, whether the patient has gone any corrective surgery, whether other risk factors are present, assessment of maternal prognosis, the heredity of cardiac lesions in the offspring.

Many developed countries has reported decreased incidence of rheumatic cardiac diseases because of extensive use of antibiotics for its management. In developing countries with limited resources like India, who are suffering from various public health burdens on health system like infectious diseases, non-communicable diseases, malnutrition as well as obesity, extensive screening of cases, early detection, prompt diagnosis and appropriate management are of paramount importance. Pregnant women with risk factors should be identified in antenatal period only using history and clinical examinations and should be dealt with in time in order to prevent complications. Majority of the cardiac diseases in pregnancy are preventable, and there is a need to inculcate this need for preventive approach for cardiac diseases like RHD.

In cases where women of reproductive age have significant cardiac lesion who develop life threatening complications during pregnancy effective contraception counselling should be done. Options include barrier methods, hormonal contraception, and sterilization. Progestin only contraception are not contraindicated in cardiac disease as they carry minimal thrombotic risks.

\section{Conclusion}

Heart diseases in pregnancy have a major impact on pregnancy and its outcome and are a high risk condition. This study results conclude that RHD is still a predominant cardiac problem affecting pregnancy and its outcome. The early detection, treatment, prevention of infections, proper follow up and correction prior to pregnancy can improve the pregnancy outcome and decrease the maternal morbidity. Heart disease in pregnancy is common public health concern in developing countries. So each patient coming to OPD or during labour even without any symptoms should be auscultated carefully by a senior doctor. Educating the community about the early ANC registration, regular ANC follow up during antenatal period, identification of risk factors in antenatal period and actions should be taken prior to onset of the disease, hence inculcating preventive approach, correction of anaemia plays a vital role. Regular antenatal screening, identification of risk factors, early diagnosis and treatment of the diagnosed heart diseases in pregnancy are recommended measures to improve the outcomes of pregnancy and hence to reduce maternal and foetal morbidities.

\section{References}

1. Ashrafi R, Curtis SL. Heart Disease and Pregnancy. Cardiol Ther [Internet]. 2017;6(2):157-73. Available from: http://link.springer.com/10.1007/s40119-017-0096-4.

2. Nqayana T, Moodley J, Naidoo DP. Cardiac disease in pregnancy. Cardiovasc J Afr [Internet]. 2008;19(3):14551. Available from: http://europepmc.org/articles/PMC3974559/?report=abstr act

3. Hiralal K, Snehamay C. Pregnancy complicated by maternal heart disease: A review of 281 women. J Obstet Gynecol India. 2012;62(3):301-6.

4. Franklin WJ, Benton MK, Parekh DR. Cardiac disease in pregnancy. Tex Heart Inst J [Internet]. 2011;38(2):151-3. Available from:

http://www.pubmedcentral.nih.gov/articlerender.fcgi?arti $\mathrm{d}=3066821 \&$ tool=pmcentrez\&rendertype $=$ abstract

5. Subbaiah M, Sharma V, Kumar S, Rajeshwari S, Kothari SS, Roy KK, et al. Heart disease in pregnancy: Cardiac and obstetric outcomes. Arch Gynecol Obstet. 2013;288(1):23-7.

6. Liu H, Xu JW, Zhao XD, Ye TY, Lin JH LQ. Pregnancy outcomes in women with heart disease. Arch Gynecol 
Obstet [Internet]. 2010;281(1):29-34. Available from: http://ovidsp.ovid.com/ovidweb.cgi?T=JS\&PAGE=refere nce $\& D=$ med5\&NEWS=N\&AN=19326134\%5Cnhttp $/ / / o v$ idsp.ovid.com/ovidweb.cgi?T=JS\&PAGE $=$ reference $\& D=$ emed9\&NEWS=N\&AN=2009625987. 